\title{
In Vivo Site-Specific Protein Tagging with Diverse Amines Using an Engineered Sortase Variant
}

\author{
Jeff E. Glasgow†, Marc L. Salit†, Jennifer R. Cochran ${ }^{*}$ \\ †National Institute of Standards and Technology, Stanford, CA. \\ $\ddagger$ Stanford University, Department of Bioengineering, Department of Chemical Engineering, \\ Stanford, CA.
}

\section{Supporting Information}

Reagents. Chemicals from Sigma unless otherwise noted. 10x Tris Buffered Saline (TBS), Tris Base, Mccoy's 5a media, fetal bovine serum, 1x Hyclone PBS and Lysogeny Broth were purchased from Thermo-Fisher Scientific (Pittsburgh, PA). Phusion polymerase, restriction enzymes and T4 DNA ligase were purchased from New England Biolabs (Ipswich, MA). Ultrapure Agarose, Terrific Broth and Deoxyribonuclease I were purchased from Invitrogen (Grand Island, NY). Isopropyl- $\beta$-D-thiogalactopyranoside (IPTG) and lysozyme were purchased from Gold Biotechnology (St. Louis, MO), and Neutravidin-HRP, Bacterial Protein Extraction Reagent (BPER) and SuperSignal West Femto Maximum Sensitivity Substrate were from Thermo Scientific (Waltham, MA). All experiments were performed using deionized, filtered water from a MilliQ system (Millipore, Billerica, MA). $0.25 \%$ Trypsin with EDTA was obtained from Life Technologies (South San Francisco, CA). Although these materials were used for our experiments, reagents from different vendors can be substituted for these items.

General Equipment. PCR and Golden Gate cloning were performed using a T100 Thermocycler (Biorad, Hercules, CA). UV/Vis spectroscopy was performed using a Nanodrop 2000 (Thermo Fisher Scientific, Pittsburgh, PA). DNA electrophoresis was performed using a BioRad Mini Sub Cell GT and Powerpac Basic (BioRad, Hercules, CA). Gels were imaged with Ethidium Bromide on a Proteinsimple Red Imager (Protein Simple, San Jose, California). Protein electrophoresis was performed using ExpressPlus PAGE Gels (12\% or 4-20\% gradient) (Genscript, Piscataway, NJ) in an XCell Novex Mini Cell (Invitrogen, Grand Island, NY) in MOPS/SDS buffer according to the manufacturer's instructions. Western Blots were performed using the iBlot system using nitrocellulose membranes (Invitrogen, Grand Island, NY), blocked with 5\% milk in TBS+ 0.5\% Tween (TBST, Sigma Aldrich, St. Louis, MO). Fluorescent imaging of SDSPAGE gels was performed with a Typhoon 9500 (GE Healthcare, Pittsburgh, PA). Mammalian cell culture was performed Thermo Scientific ${ }^{\mathrm{TM}}$ Heracell $^{\mathrm{TM}} 150 \mathrm{i}$ $\mathrm{CO}_{2}$ incubators at $5 \% \mathrm{CO}_{2}$. Flow cytometry was performed on a LSRII flow cytometer (BD Biosciences, San Jose, CA) at the Stanford Shared FACS Facility. Although this 
equipment was used for our experiments, products from different vendors can be substituted for these items.

Peptide Synthesis. Solid phase peptide synthesis (SPPS) was performed on a CS Bio CS336 instrument (Menlo Park, CA), using 9-fluorenylmethyloxycarbonyl (Fmoc)protected amino acids and Rink amide resin (CS Bio). Fmoc groups were removed with $20 \%$ piperidine in $\mathrm{N}, \mathrm{N}$-dimethylformamide (DMF). Amino acid coupling was performed using 1-hydroxybenzotriazole/diisopropylcarbodiimide (HOBT/DIC) chemistry in DMF. Peptides were synthesized with a $2 \mathrm{~h}$ coupling/washing/deprotection cycle. Side-chain deprotection and resin cleavage was performed by suspending the resin in $10 \mathrm{ml}$ of a 94:2.5:1:2.5 (v/v) mixture of trifluoroacetic acid (TFA): 1,2ethanedithiol:triisopropylsilane:water for $2 \mathrm{~h}$ at room temperature open to air. Resin was filtered off, and crude peptides were precipitated with 10 volumes of diethyl ether cooled to $-80{ }^{\circ} \mathrm{C}$, isolated by filtration, and washed with diethyl ether. The peptide was then resuspended in water with $0.1 \%$ TFA and purified by preparative reverse-phase HPLC on Varian Prostar instrument using a Vydac C18 column, and eluted with a linear gradient of $90 \%$ acetonitrile with $0.1 \%$ TFA over $20 \mathrm{~min}$. Chromatography was followed by UV absorbance at $220 \mathrm{~nm}$, and fractions containing peptide were collected, frozen in dry ice, and lyophilized.

Mass Spectrometry. Peptide Liquid Chromatography/Mass spectrometry (LC/MS) was performed using a Shimadzu 2020 Liquid Chromatograph Mass Spectrometer (Shimadzu). Peptide samples were run on a Synergi 4u Hydro-RP $80 \AA 30$ x $2.0 \mathrm{~mm}$ column (Phenomenex). Protein samples were analyzed using an Agilent 1200 series HPLC in line with an Agilent 6224 TOF mass spectrometer with a Turbospray ion source. Protein samples were run on a Poroshell 300SB-C18 column (Agilent Technologies). Protein mass reconstruction was performed with Mass Hunter software (Agilent, USA).

Molecular Biology. Cloning was performed using standard molecular biology techniques. Plasmid pET30b-SrtA5M was obtained as a generous gift from Brian McNaughton (Colorado State University). Constructs cloned into pTrc99a were amplified using 5' NcoI site and a 3' BamHI site. Constructs in pRha were cloned into a custommade rhamnose inducible vector (pRhaGG, DNA2.0) using Golden Gate cloning with 5' and 3' BsaI sites. Constructs in pET22b were cloned using Golden Gate cloning by amplifying the pET22b backbone with primers 152 and 153, installing BsaI restriction sites. All plasmids were transformed into chemically competent DH5 $\alpha$ cells and plated on appropriate antibiotics. Sortase 7M (SrtA7M) in pTrc99a was generated from pTrc99a-SrtA5M by quick change mutagenesis using primers 41 and 42 .

\begin{tabular}{|l|l|l|}
\hline Primers & Sequence & Description \\
\hline JEG28_malE_R & $\begin{array}{l}\text { ACCATTGGTCTCTGCCGTTACTTGGTGATACG } \\
\text { AGTCTGCG }\end{array}$ & $\begin{array}{l}\text { Cloning MBP into } \\
\text { pRhaGG }\end{array}$ \\
\hline JEG31_malEdF & $\begin{array}{l}\text { ACCATTGGTCTCAGGTAAAAATGAAAATCGA } \\
\text { AGAAGGTAAACTGG }\end{array}$ & \\
\hline
\end{tabular}




\begin{tabular}{|c|c|c|}
\hline JEG41 & $\begin{array}{l}\text { GAGGTGTAAGCTTTGCAAAAGAAAATCAATC } \\
\text { ACTAGATGATCAAAATATTTC }\end{array}$ & \multirow{2}{*}{ Quikchange $5 \mathrm{M}$ to $7 \mathrm{M}$} \\
\hline JEG42 & $\begin{array}{l}\text { GAAATATTTTGATCATCTAGTGATTGATTTTCT } \\
\text { TTTGCAAAGCTTACACCTC }\end{array}$ & \\
\hline JEG60_malE_Srt_R & $\begin{array}{l}\text { ACCATTGGTCTCTGCCGTTAGCCACCGGTTTC } \\
\text { CGGCAGGCTGCCCTTGGTGATACGAGTCTGCG }\end{array}$ & $\begin{array}{l}\text { Cloning MBP-Srt into } \\
\text { pRhaGG }\end{array}$ \\
\hline JEG92_SrtPT_F & $\begin{array}{l}\text { ACCATTGGTCTCTCATGCAAGCTAAACCTCAA } \\
\text { ATTC }\end{array}$ & \multirow{2}{*}{$\begin{array}{l}\text { Cloning SrtA variants into } \\
\text { pTrc99a }\end{array}$} \\
\hline JEG93_SrtPR_R & TAGCAAGGATCCGTTAGCAGCCGGATCTCAG & \\
\hline JEG127_GFP_F & $\begin{array}{l}\text { ACCATTGGTCTCTGGTAAAAATGCATCACCAT } \\
\text { CACCATCACCGTAAAGGCGAAGAGCTG }\end{array}$ & \multirow{2}{*}{ Cloning His-sfGFP-srt } \\
\hline JEG128_GFP_R & $\begin{array}{l}\text { ACCATTGGTCTCTGCCGTTAACCGGTTTCCGG } \\
\text { CAGGCTGCCTTTGTACAGTTCATCCATACCAT }\end{array}$ & \\
\hline JEG144_SGSH_F & $\begin{array}{l}\text { ACCATTGGTCTCTGGTAAAAATGCGTAAAGGC } \\
\text { GAAGAGCTG }\end{array}$ & \multirow[b]{2}{*}{$\begin{array}{l}\text { Cloning sfGFP-His-Srt } \\
\text { into pET22 }\end{array}$} \\
\hline JEG145_SGSH_R & $\begin{array}{l}\text { ACAGGTCTCTGCCGTTAACCACCGGTTTCCGG } \\
\text { CAGGTGATGGTGATGGTGATGTTTGTACAGTT } \\
\text { CATCCATACCAT }\end{array}$ & \\
\hline JEG146_Srt_Rh_F & $\begin{array}{l}\text { ATTGGTCTCTGGTAAAAATGCAAGCTAAACCT } \\
\text { CAAATTC }\end{array}$ & \multirow{2}{*}{$\begin{array}{l}\text { Cloning SrtA into } \\
\text { pRhaGG }\end{array}$} \\
\hline JEG147_Srt_Rh_R & ACAGGTCTCTGCCGTTAGCAGCCGGATCTCAG & \\
\hline JEG152_p22_F & TCAAGGTCTCGCGGCTGCTGCTGGTCTGCTGC & \multirow{2}{*}{$\begin{array}{l}\text { Reverse PCR pET22b for } \\
\text { Golden Gate }\end{array}$} \\
\hline JEG153_p22_R & $\begin{array}{l}\text { GTAAGGTCTCTTACCTCTCCTTCTTAAAGTTAA } \\
\text { ACAAAATT }\end{array}$ & \\
\hline JEG156_Nan_Rh_F & $\begin{array}{l}\text { ACCATTGGTCTCTGGTAAAAATGGAAGTGCAG } \\
\text { CTGGTGGAAAG }\end{array}$ & \multirow{2}{*}{$\begin{array}{l}\text { Cloning Nanobody } 5 f 7- \\
\text { His-Srt into pET22 }\end{array}$} \\
\hline JEG157_Nan_Rh_R & $\begin{array}{l}\text { ACAGGTCTCTGCCGTTAACCACCGGTTTCCGG } \\
\text { CAGGTGATGGTGATGGTGATGGCTGCTCACGG } \\
\text { TCACCTG }\end{array}$ & \\
\hline JEG160_Fn10_F & $\begin{array}{l}\text { ACCATTGGTCTCTGGTAAAAATGCTGGTTCCG } \\
\text { CGTGGATC }\end{array}$ & \multirow{2}{*}{$\begin{array}{l}\text { Cloning Fibronectin } \\
\text { FN10-His-Srt into pET22 }\end{array}$} \\
\hline JEG161_FnHS_R & $\begin{array}{l}\text { ACAGGTCTCTGCCGTTAACCACCGGTTTCCGG } \\
\text { CAGGTGATGGTGATGGTGATGACCGCCTTTAC } \\
\text { CTTTTTTACC }\end{array}$ & \\
\hline JEG162_GST_F & $\begin{array}{l}\text { ACCATTGGTCTCTGGTAAAAATGCCACCATAC } \\
\text { ACCGTTGTTTAC }\end{array}$ & \multirow{2}{*}{$\begin{array}{l}\text { Cloning Glutathione-S- } \\
\text { transferase-His-Srt into } \\
\text { pET22 }\end{array}$} \\
\hline JEG163_GSTHS_R & $\begin{array}{l}\text { ACAGGTCTCTGCCGTTAACCACCGGTTTCCGG } \\
\text { CAGGTGATGGTGATGGTGATGTTGCTTCCCGT } \\
\text { TTCCG }\end{array}$ & \\
\hline JEG129_Trx_F & $\begin{array}{l}\text { ACCATTGGTCTCAGGTAAAAATGAGCGATAA } \\
\text { AATTATTCACC }\end{array}$ & \multirow{2}{*}{$\begin{array}{l}\text { Installing thioredoxin tag } \\
\text { on to Nanobody } 5 \mathrm{f} 7 \text { in } \\
\text { pET22 }\end{array}$} \\
\hline JEG130_Trx_R & $\begin{array}{l}\text { ATATCAGGTCTCTCAGACTTGTCGTCGTCGTC } \\
\text { GG }\end{array}$ & \\
\hline JEG165_NB_Trx & $\begin{array}{l}\text { ACCATTGGTCTCTTCTGGCATGGAAGTGCAGC } \\
\text { TGGTGGAAAG }\end{array}$ & $\begin{array}{l}\text { Cloning Nanobody fusion } \\
\text { Trx-5f7-His-srt }\end{array}$ \\
\hline JEG58 & $\begin{array}{l}\text { ACCATTGCTCTTCTTGACCACTGAGATCCGGC } \\
\text { TG }\end{array}$ & \multirow{2}{*}{$\begin{array}{l}\text { Reverse PCR pET20b } \\
\text { with SapI sites }\end{array}$} \\
\hline JEG59 & $\begin{array}{l}\text { ACGATAGCTCTTCTCTCCTTCTTAAAGTTAAA } \\
\text { CAAAAT }\end{array}$ & \\
\hline JEG63 & $\begin{array}{l}\text { ACCATTGCTCTTCTGAGATAAATACATGCAAG } \\
\text { CTAAACCTCAAATTC }\end{array}$ & \multirow{2}{*}{$\begin{array}{l}\text { Cloning SrtA } \Delta 59 \text { into } \\
\text { pET20b with SapI }\end{array}$} \\
\hline JEG64 & $\begin{array}{l}\text { ACGATAGCTCTTCTTCAGTTAGCAGCCGGATC } \\
\text { TCAG }\end{array}$ & \\
\hline
\end{tabular}




\section{Protein expression and purification}

Sortase variants. Sortase $5 \mathrm{M}$ and $7 \mathrm{M}$ and wild-type SrtA $\Delta 59$ were expressed and purified in E. coli. Plasmid pET30b-SrtA5M was transformed into BL21(DE3)pLysS cells (Invitrogen). Colonies grown on LB agar containing $50 \mu \mathrm{g} / \mathrm{ml} \mathrm{kanamycin} \mathrm{and} 34$ $\mu \mathrm{g} / \mathrm{ml}$ chloramphenicol were inoculated into $5 \mathrm{ml} \mathrm{LB}$ media containing the same antibiotics and grown overnight at $37^{\circ} \mathrm{C}$. Cells were then subcultured $1 / 100$ into $500 \mathrm{ml}$ of TB media containing $100 \mu \mathrm{g} / \mathrm{ml}$ kanamycin and $34 \mu \mathrm{g} / \mathrm{ml}$ chloramphenicol and grown until cells reached mid-log phase (OD $\sim 0.4$ ). Expression of the sortase variant was induced with $1 \mathrm{mM}$ IPTG. Cells were allowed to express protein overnight at $37^{\circ} \mathrm{C}$. Cells were then harvested by centrifugation at $4000 \mathrm{x} g$ and resuspended in BPER (Pierce) with $0.6 \mathrm{mg} / \mathrm{ml}$ lysozyme by vortexing. Deoxyribonuclease was added and suspension was incubated at room temperature for $10 \mathrm{~min}$ with frequent vortexing. Insoluble material was pelleted at $15000 \mathrm{x} g$ for $15 \mathrm{~min}$. The soluble fraction was applied to $1 \mathrm{ml}$ of $\mathrm{Ni}^{2+} / \mathrm{NTA}$ resin preequilibrated with wash buffer $(50 \mathrm{mM}$ TrisHCl, $300 \mathrm{mM}$ $\mathrm{NaCl}, 20 \mathrm{mM}$ imidazole $\mathrm{pH}$ 7.4). The resin was washed with another $60 \mathrm{ml}$ of wash buffer. Proteins were eluted with elution buffer ( $50 \mathrm{mM}$ TrisHCl, $300 \mathrm{mM} \mathrm{NaCl}, 300$ $\mathrm{mM}$ imidazole $\mathrm{pH}$ 7.4). The protein solution was dialyzed into 1xTBS (Fisher) using Slide-A-Lyzer dialysis cassettes (Pierce), concentrated using a 10,000 Da MWCO centrifugal filter (Millipore, Billerica, MA), and stored at $4{ }^{\circ} \mathrm{C}$. Wild-type SrtA $\Delta 59$ was amplified from pGBMCS-SortA (Addgene) and cloned into pET20b using SapI Golden Gate cloning, and expressed similarly, with the addition of $10 \%$ glycerol to the purification buffers.

GFP-His-Srt, Nanobody-His-Srt, Fibronectin-His-Srt, Glutathione-S-transferase-His-Srt. Plasmid pET22 containing the gene of interest was transformed into BL21(DE3) cells, which were then plated on $\mathrm{LB}+100 \mu \mathrm{g} / \mathrm{ml}$ ampicillin. Colonies were inoculated into $\mathrm{LB}+\mathrm{Amp}$ and grown overnight, then subcultured 1/100 into 100-1000 ml LB+Amp, grown to mid-log phase, and induced with $1 \mathrm{mM}$ (final) IPTG and cooled to $30^{\circ} \mathrm{C}$. Protein was expressed overnight at $30^{\circ} \mathrm{C}$. Cells were then harvested by centrifugation at $4000 \mathrm{x} g$ and resuspended in BPER (Pierce) with $0.6 \mathrm{mg} / \mathrm{ml}$ lysozyme by vortexing. Deoxyribonuclease was added and suspension was incubated at room temperature for 10 min with frequent vortexing. Insoluble material was pelleted at $15000 \times \mathrm{g}$ for $15 \mathrm{~min}$. The soluble fraction was applied to $1 \mathrm{ml}$ of $\mathrm{Ni}^{2+} / \mathrm{NTA}$ resin preequilibrated with wash buffer (50 mM TrisHCl, $300 \mathrm{mM} \mathrm{NaCl}, 20 \mathrm{mM}$ imidazole $\mathrm{pH}$ 7.4). The resin was washed with another $60 \mathrm{ml}$ of wash buffer. Proteins were eluted with elution buffer $(50 \mathrm{mM} \mathrm{TrisHCl}$, $300 \mathrm{mM} \mathrm{NaCl}, 300 \mathrm{mM}$ imidazole $\mathrm{pH}$ 7.4). The protein solution was dialyzed into 1xTBS (Fisher) using Slide-A-Lyzer dialysis cassettes (Pierce), concentrated using a 10,000 Da MWCO centrifugal filter (Millipore, Billerica, MA), and stored at $4{ }^{\circ} \mathrm{C}$.

Maltose Binding Protein-Srt (MBP). MBP without its N-terminal periplasmic localization tag, containing a C-terminal LPETGG was expressed from pRha in DH5a. The plasmid was transformed into the cells, which were then plated on $\mathrm{LB}+50 \mu \mathrm{g} / \mathrm{ml}$ kanamycin. Colonies were inoculated into LB+Kan and grown overnight, then subcultured 1/100 into $100 \mathrm{ml}$ of $\mathrm{LB}+\mathrm{Kan}$, grown to mid-log phase, and induced with $4 \mathrm{mM}$ (final) rhamnose. Protein was expressed overnight at $37^{\circ} \mathrm{C}$. The next day cells were harvested and lysed with BPER+0.6 mg/ml lysozyme, followed by digestion with 2 units of DNase I. The 
lysate was clarified by centrifugation at $14,000 \mathrm{xg}$, and the supernatant was applied to a $1 \mathrm{ml}$ MBP-Trap column (GE Healthcare). The bound protein was washed with $10 \mathrm{ml}$ of Buffer A (100 mM Tris, $300 \mathrm{mM} \mathrm{NaCl}, 1 \mathrm{mM}$ EDTA, pH 7.2) and then eluted with $5 \mathrm{ml}$ of Buffer $\mathrm{A}+10 \mathrm{mM}$ maltose. The protein was concentrated and buffer exchanged into $10 \mathrm{mM}$ phosphate buffer using $10 \mathrm{kDa}$ MWCO centrifugal filters.

In vitro conjugation of peptides. Synthetic LPETGSW peptide was resuspended to 20 $\mathrm{mM}$ in water. Stock solutions $(50 \mathrm{mM})$ of each amine were made in $50 \mathrm{mM}$ acetic acid. Reactions consisting of $1 \mathrm{mM}$ peptide, $10 \mathrm{mM}$ amine, $100 \mathrm{mM}$ ammonium bicarbonate, and $20 \mu \mathrm{M}$ SrtA7M (10 $\mu \mathrm{l}$ final volume) were incubated at $37^{\circ} \mathrm{C}$ for $2 \mathrm{~h}$ with occasional mixing. Reactions were quenched with the addition of 9 volumes of $0.2 \%$ formic acid and analyzed by LC/ESI-Quadrupole MS.

The $\mathrm{pH}$ dependence of the enzyme was analyzed as above, except in $100 \mathrm{mM}$ Tris $\bullet \mathrm{HCl}$ at the $\mathrm{pH}$ described. Reactions were allowed to proceed at $37^{\circ} \mathrm{C}$ for $2 \mathrm{~h}$, followed by formic acid quenching and LC/MS as described.

Peptide labeling with wild-type SrtA $\Delta 59$ was performed in $25 \mathrm{mM}$ Tris $\mathrm{pH} 7.5,150 \mathrm{mM}$ $\mathrm{NaCl}, 10 \mathrm{mM} \mathrm{CaCl}{ }_{2}$. Enzyme $(10 \mu \mathrm{M}$ or $150 \mu \mathrm{M}$ final) was added to buffer containing $10 \mathrm{mM}$ amine of interest and $1 \mathrm{mM}$ peptide. Reactions were allowed to proceed for 2 or $20 \mathrm{~h}$, followed by quenching and LC/MS analysis as described.

In vitro conjugation of proteins. Purified MBP-srt, His-sfGFP-srt, Nanobody-His-srt, Glutathione-S-transferase-His-srt, Fibronectin-His-srt, and sfGFP-His-srt were labeled after purification in $100 \mathrm{mM}$ ammonium bicarbonate buffer $\mathrm{pH}$ 7.8. MBP-Srt, HissfGFP-Srt, sfGFP-His-srt, and Glutathione-S-transferase-His-Srt were labeled at a final concentration of $100 \mu \mathrm{M}$, while Nanobody-His-Srt, and Fibronectin-His-Srt were labeled at final concentrations of $80 \mu \mathrm{M}$ and $50 \mu \mathrm{M}$, respectively, due to solubility issues. Concentrated Azp and propargylamine were each mixed with $1 \mathrm{M}$ acetic acid to a final concentration of $1 \mathrm{M}$ and added to the reaction at a final concentration of $100 \mathrm{mM}$. The reaction was initiated with the addition of SrtA7M and incubated at $37^{\circ} \mathrm{C}$ for $8 \mathrm{~h}$. Each reaction was then quenched with 9 volumes of $0.2 \%$ formic acid and analyzed by LC/ESI-TOF-MS.

Coexpression, conjugation, and purification of MBP variants. MBP-srt in $p R$ ha and the SrtA 7M in pTrc99a were cotransformed into DH5 $\alpha$ cells. Colonies grown on LB agar with $50 \mu \mathrm{g} / \mathrm{ml}$ kanamycin and $100 \mu \mathrm{g} / \mathrm{ml}$ ampicillin were grown inoculated into $2 \mathrm{ml}$ LB media with the same antibiotics and grown overnight at $37^{\circ} \mathrm{C}$. Overnight cultures were subcultured 1/100 into 2-25 $\mathrm{ml}$ of the desired media with the appropriate antibiotics, supplemented with $5 \mathrm{mM} \mathrm{CaCl}_{2}$ and $5 \mathrm{mM} \mathrm{MgCl}_{2}$. After $2 \mathrm{~h}$ growth at $37^{\circ} \mathrm{C}$, expression of MBP was induced with $4 \mathrm{mM}$ rhamnose. Sortase was not induced. At this time the desired concentration of Azp was added. Background expression of sortase was sufficient to see significant conjugation. Cells were allowed to express and modify the MBP for 20 h. $500 \mu 1$ of the cells were harvested by centrifugation and washed three times with TBS. Cells were then resuspended in $100 \mu 1$ BPER with $0.6 \mathrm{mg} / \mathrm{ml}$ lysozyme and 0.5 units of 
DNase. Lysate was then clarified by centrifugation at $15,000 \mathrm{xg}$ at $4{ }^{\circ} \mathrm{C}$ for $10 \mathrm{~min}$. Clarified lysate was then analyzed directly or carried through to purification.

MBP variants were purified using a $1 \mathrm{ml}$ MBP-trap column (GE Healthcare Pittsburgh, PA). The lysate was applied to the column preequilibrated with $2 x T B S$ with $1 \mathrm{mM}$ EDTA. The bound protein was washed with $10 \mathrm{ml}$ of the same buffer, followed by elution with $5 \mathrm{ml}$ of the same buffer with $10 \mathrm{mM}$ maltose. Protein was concentrated and desalted using $30 \mathrm{kDa}$ MWCO spin filters (Millipore, Billerica, MA).

Coexpression, conjugation, and purification of Trx-Nanobody-His-srt, GlutathioneS-transferase-His-srt, and sfGFP-His-srt. The desired target protein in pET22b was cotransformed with pRha-SrtA7M into BL21(DE3) cells (Invitrogen). Colonies grown on LB agar with $50 \mu \mathrm{g} / \mathrm{ml}$ kanamycin and $100 \mu \mathrm{g} / \mathrm{ml}$ ampicillin were inoculated into $2 \mathrm{ml}$ LB media with the same antibiotics and $1 \mathrm{mM}$ rhamnose and grown overnight at $37^{\circ} \mathrm{C}$. Overnight cultures were subcultured 1/100 into 2-25 $\mathrm{ml}$ of LB with the appropriate antibiotics, supplemented with $5 \mathrm{mM} \mathrm{CaCl}_{2}, 5 \mathrm{mM} \mathrm{MgCl}_{2}$, and $1 \mathrm{mM}$ rhamnose. After 2 $\mathrm{h}$ growth at $37^{\circ} \mathrm{C}$, expression of the target protein was induced with $1 \mathrm{mM}$ (final) IPTG and the desired concentration of Azp or propargylamine was added and the temperature was lowered to $30^{\circ} \mathrm{C}$. Cells were allowed to express and modify the desired protein for $20 \mathrm{~h} .500 \mu \mathrm{l}$ of the cells were harvested by centrifugation and washed three times with TBS. Cells were then resuspended in $100 \mu 1$ BPER with $0.6 \mathrm{mg} / \mathrm{ml}$ lysozyme and 0.5 units of DNase and $50 \mathrm{mM}$ iodoacetamide. Lysate was then clarified by centrifugation at $15,000 \mathrm{x} \mathrm{g}$ at $4{ }^{\circ} \mathrm{C}$ for $10 \mathrm{~min}$. Clarified lysate was then analyzed directly or carried through to purification. Azp- or propargylamine-conjugated, His-tagged proteins were purified as described above.

Analysis of Azp conjugation by fluorescent labeling. Lysate from in vivo experiments (30 $\mu 1$ ) was incubated with $500 \mu \mathrm{M}$ Cy3-DBCO (Sigma) overnight at room temperature. The following day, any insoluble material was pelleted by centrifugation at $15000 \mathrm{x} g$, and $15 \mu \mathrm{l}$ of the remaining lysate was run on a 4-20\% gradient SDS-PAGE gel. The gel was imaged for fluorescence followed by staining with Coomassie.

Analysis of Azp conjugation by western blot. Lysate from in vivo experiments was directly labeled with Sulfo-dibenzocyclooctyne (DIBAC)-biotin (Sigma). The reaction was initiated by adding the biotin-DIBAC $(0.6 \mu 1,50 \mathrm{mM}$ in DMF) directly to lysate (30 $\mu 1)$ containing Azp-labeled proteins. The solution was incubated at room temperature for $3 \mathrm{~h}$ with occasional mixing. Then $12 \mu \mathrm{l}$ of $4 \mathrm{X}$ LDS buffer and $4 \mu \mathrm{l}$ of 10x reducing agent (Invitrogen) were added to each sample, followed by heating at $95^{\circ} \mathrm{C}$ for $10 \mathrm{~min}$. The samples were cooled and run on a 12\% SDS-PAGE gel (Genscript) at $125 \mathrm{~V}$ for $65 \mathrm{~min}$, followed by transfer to a nitrocellulose membrane using the iBlot system (Invitrogen). The membrane was blocked with 5\% milk in TBST for $1 \mathrm{~h}$. The membrane was then stained with a 1/1000 dilution of neutravidin-HRP (Thermo-Pierce) in 5\% milk in TBST for $1 \mathrm{~h}$ at room temperature. Unbound neutravidin-HRP was washed from the blot three times with TBST for 5 min each. The blot was then imaged using SuperSignal West Femto Maximum Sensitivity Substrate (Thermo-Pierce). 
Coexpression, conjugation, and purification of Trx-Nanobody-His-srt for HER2binding assays. Thioredoxin-fused nanobody $5 f 7$ (in pET22) was coexpressed with SrtA7M (in pRha) as described above in $50 \mathrm{ml}$ of LB with $100 \mu \mathrm{g} / \mathrm{ml}$ ampicillin, 50 $\mu \mathrm{g} / \mathrm{ml}$ kanamycin, $5 \mathrm{mM} \mathrm{MgCl} 2,5 \mathrm{mM} \mathrm{CaCl}_{2}$, and $1 \mathrm{mM}$ rhamnose. An overnight culture was subcultured $1 / 100$ and grown at $37^{\circ} \mathrm{C}$ for $2 \mathrm{~h}$ followed by addition of IPTG to $1 \mathrm{mM}$ and Azp to $25 \mathrm{mM}$ (pH adjusted to 7 with acetic acid). The cells were allowed to express and label for $24 \mathrm{~h}$ at $30^{\circ} \mathrm{C}$. Cells were then harvested and lysed with $5 \mathrm{ml} \mathrm{BPER+1}$ $\mathrm{mg} / \mathrm{ml}$ lysozyme and 0.5 units of DNase. The lysate was clarified by centrifugation at $14,000 \mathrm{x} \mathrm{g}$ for 10 minutes and applied to $0.5 \mathrm{ml} \mathrm{Ni}{ }^{2+} / \mathrm{NTA}$ resin. The resin was washed with $20 \mathrm{ml}$ of wash buffer ( $50 \mathrm{mM}$ TrisHCl, $300 \mathrm{mM} \mathrm{NaCl}, 20 \mathrm{mM}$ imidazole $\mathrm{pH}$ 7.4). 1 $\mathrm{ml}$ of $100 \mu \mathrm{M}$ Cy3-DBCO was then added to the resin, transferred to a $15 \mathrm{ml}$ falcon tube, followed by $1 \mathrm{ml}$ wash buffer to transfer any remaining resin. The mixture allowed to react overnight at room temperature with agitation. The resin was transferred back to the column and washed with an additional $20 \mathrm{ml}$ wash buffer. The bright red protein was then eluted with $4 \mathrm{ml}$ wash buffer with $300 \mathrm{mM}$ imidazole. This was concentrated and buffer exchanged using a $10 \mathrm{kDa}$ MWCO centrifugal filter and used without further purification. Protein concentration was obtained using the "dyes and labels" setting on a Nanodrop.

Purification of unlabeled Trx-5f7. pET22 containing the gene for Trx-5f7 was transformed into Shuffle T7 cells (New England Biolabs) and plated on LB with 100 $\mu \mathrm{g} / \mathrm{ml}$ ampicillin. A single colony was used to inoculate liquid LB+Amp and grown overnight at $37^{\circ} \mathrm{C}$. The overnight was subcultured $1 / 100$ in $50 \mathrm{ml}$ of LB with $100 \mu \mathrm{g} / \mathrm{ml}$ ampicillin, $5 \mathrm{mM} \mathrm{MgCl} 2,5 \mathrm{mM} \mathrm{CaCl}_{2}$, grown for $2 \mathrm{~h}$ and induced with $1 \mathrm{mM}$ IPTG. The cells were allowed to express and label for $24 \mathrm{~h}$ at $30{ }^{\circ} \mathrm{C}$. Cells were then harvested and lysed with $5 \mathrm{ml} \mathrm{BPER}+1 \mathrm{mg} / \mathrm{ml}$ lysozyme and 0.5 units of DNase. The lysate was clarified by centrifugation at $14,000 \mathrm{x}$ for 10 minutes and applied to $0.5 \mathrm{ml} \mathrm{Ni}^{2+} / \mathrm{NTA}$ resin. The resin was washed with $40 \mathrm{ml}$ of wash buffer $(50 \mathrm{mM}$ TrisHCl, $300 \mathrm{mM} \mathrm{NaCl}$, $20 \mathrm{mM}$ imidazole $\mathrm{pH}$ 7.4). The protein was then eluted with $4 \mathrm{ml}$ wash buffer with 300 $\mathrm{mM}$ imidazole, concentrated and buffer exchanged using a $10 \mathrm{kDa}$ MWCO centrifugal filter and used without further purification. Protein concentration was obtained using the Protein A280 setting on a Nanodrop.

Flow cytometry analysis of labeled nanobody binding. SK-BR-3 cells (ATCC) were cultured in a T75 flask using Mccoy's 5a media supplemented with $10 \%$ FBS. Cells at $80 \%$ confluence were treated with $3 \mathrm{ml}$ of $0.25 \%$ trypsin/EDTA for 3 minutes, followed by quenching with $8 \mathrm{ml}$ fresh media. Cells were washed three times with Hyclone PBS by centrifugation at $1000 \mathrm{x}$ g for 3 minutes and resuspension in $8 \mathrm{ml} \mathrm{PBS}$, and finally resuspended in Hyclone PBS with $0.1 \%$ BSA to a final concentration of 400,000 cells $/ \mathrm{ml}$ and kept on ice for the remainder of the protocol. A $100 \mu 1$ solution of this, containing 40,000 cells, was treated with either $100 \mathrm{nM}$ labeled Trx-5f7 alone, or pretreated (20 minutes) with $10 \mu \mathrm{M}$ unlabeled Trx-5f7. Nanobody-cell mixtures were incubated on ice for 20 minutes with occasional agitation. Cells were then washed twice and pelleted. Cells were then resuspended in PBS $+0.1 \%$ BSA $(150 \mu 1)$ immediately before analysis by flow cytometry. Histograms were generated using FlowJo. 


\section{Sequences. \\ SrtA7M}

ATGCAAGCTAAACCTCAAATTCCGAAAGATAAATCAAAAGTGGCAGGCTATATTGAAATTCCAGATGCTGATATTAAA GAACCAGTATATCCAGGACCAGCAACACGCGAACAATTAAATAGAGGTGTAAGCTTTGCAAAAGAAAATCAATCACTA GATGATCAAAATATTTCAATTGCAGGACACACTTTCATTGACCGTCCGAACTATCAATTTACAAATCTTAAAGCAGCCA AAAAAGGTAGTATGGTGTACTTTAAAGTTGGTAATGAAACACGTAAGTATAAAATGACAAGTATAAGAAACGTTAAGC CAACAGCTGTAGAAGTTCTAGATGAACAAAAAGGTAAAGATAAACAATTAACATTAATTACTTGTGATGATTACAATG AAGAGACAGGCGTTTGGGAAACACGTAAAATCTTTGTAGCTACAGAAGTCAAACTCGAGCACCACCACCACCACCACT GA

\section{WT SrtA 459}

ATGCAAGCTAAACCTCAAATTCCGAAAGATAAATCAAAAGTGGCAGGCTATATTGAAATTCCAGATGCTGATATTAAA GAACCAGTATATCCAGGACCAGCAACACCTGAACAATTAAATAGAGGTGTAAGCTTTGCAGAAGAAAATGAATCACTA GATGATCAAAATATTTCAATTGCAGGACACACTTTCATTGACCGTCCGAACTATCAATTTACAAATCTTAAAGCAGCCA AAAAAGGTAGTATGGTGTACTTTAAAGTTGGTAATGAAACACGTAAGTATAAAATGACAAGTATAAGAGATGTTAAGC CAACAGATGTAGAAGTTCTAGATGAACAAAAAGGTAAAGATAAACAATTAACATTAATTACTTGTGATGATTACAATG AAAAGACAGGCGTTTGGGAAAAACGTAAAATCTTTGTAGCTACAGAAGTCAAACTCGAGCACCACCACCACCACCACT GA

\section{pRhaGG}

ATCAATACCATATTTTTGAAAAAGCCGTTTCTGTAATGAAGGAGAAAACTCACCGAGGCAGTTCCATAGGATGGCAAG ATCCTGGTATCGGTCTGCGATTCCGACTCGTCCAACATCAATACAACCTATTAATTTCCCCTCGTCAAAAATAAGGTTAT CAAGTGAGAAATCACCATGAGTGACGACTGAATCCGGTGAGAATGGCAAAAGTTTATGCATTTCTTTCCAGACTTGTTC AACAGGCCAGCCATTACGCTCGTCATCAAAATCACTCGCATCAACCAAACCGTTATTCATTCGTGATTGCGCCTGAGCG AGGCGAAATACGCGATCGCTGTTAAAAGGACAATTACAAACAGGAATCGAGTGCAACCGGCGCAGGAACACTGCCAG CGCATCAACAATATTTTCACCTGAATCAGGATATTCTTCTAATACCTGGAACGCTGTTTTTCCGGGGATCGCAGTGGTG AGTAACCATGCATCATCAGGAGTACGGATAAAATGCTTGATGGTCGGAAGTGGCATAAATTCCGTCAGCCAGTTTAGT CTGACCATCTCATCTGTAACATCATTGGCAACGCTACCTTTGCCATGTTTCAGAAACAACTCTGGCGCATCGGGCTTCCC ATACAAGCGATAGATTGTCGCACCTGATTGCCCGACATTATCGCGAGCCCATTTATACCCATATAAATCAGCATCCATG TTGGAATTTAATCGCGGCCTCGACGTTTCCCGTTGAATATGGCTCATAGCTCCTGAAAATCTCGATAACTCAAAAAATA CGCCCGGTAGTGATCTTATTTCATTATGGTGAAAGTTGGAACCTCTTACGTGCCGATCAAGAAGACGGTCAAAAGCCTC CGGTCGGAGGCTTTTGACTTTCTGCTATGGAGGTCAGGTATGATTTAAATGGTCAGTATTGAGCGATATCTAGAGAATT CGTCCACCACAATTCAGCAAATTGTGAACATCATCACGTTCATCTTTCCCTGGTTGCCAATGGCCCATTTTCCTGTCAGT AACGAGAAGGTCGCGAATTCAGGCGCTTTTTAGACTGGTCGTATGAAATTCTTTTAAGGAGGTAAGAGACCTCCCCTAT CAGTGATAGAGATTGACATCCCTATCAGTGATAGAGATACTGAGCACGGATCTTAGCTACTAGAGAAAGAGGAGAAAT ACTAGATGCGTAAAGGCGAAGAGCTGTTCACTGGTGTCGTCCCTATTCTGGTGGAACTGGATGGTGATGTCAACGGTCA TAAGTTTTCCGTGCGTGGCGAGGGTGAAGGTGACGCAACTAATGGTAAACTGACGCTGAAGTTCATCTGTACTACTGGT AAACTGCCGGTACCTTGGCCGACTCTGGTAACGACGCTGACTTATGGTGTTCAGTGCTTTGCTCGTTATCCGGACCATAT GAAGCAGCATGACTTCTTCAAGTCCGCCATGCCGGAAGGCTATGTGCAGGAACGCACGATTTCCTTTAAGGATGACGG CACGTACAAAACGCGTGCGGAAGTGAAATTTGAAGGCGATACCCTGGTAAACCGCATTGAGCTGAAAGGCATTGACTT TAAAGAAGACGGCAATATCCTGGGCCATAAGCTGGAATACAATTTTAACAGCCACAATGTTTACATCACCGCCGATAA ACAAAAAAATGGCATTAAAGCGAATTTTAAAATTCGCCACAACGTGGAGGATGGATCTGTGCAGCTGGCTGATCACTA CCAGCAAAACACTCCAATCGGTGATGGTCCTGTTCTGCTGCCAGACAATCACTATCTGAGCACGCAAAGCGTTCTGTCT AAAGATCCGAACGAGAAACGCGATCATATGGTTCTGCTGGAGTTCGTAACCGCAGCGGGCATCACGCATGGTATGGAT GAACTGTACAAATGAGGTCTCGCGGCCGCCACCGCTGAGCAATAACTAGCATAACCCCTTGGGGCCTCTAAACGGGTC TTGAGGGGTTTTTTGCTGAAAGGAGGAACTATATCCGGGTAACGAATTCAAGCTTGATATCATTCAGGACGAGCCTCAG ACTCCAGCGTAACTGGACTGCAATCAACTCACTGGCTCACCTTCACGGGTGGGCCTTTCTTCGGTAGAAGTCTTCTTAAT AAGATGATCTTCTTGAGATCGTTTTGGTCTGCGCGTAATCTCTTGCTCTGAAAACGAAAAAACCGCCTTGCAGGGCGGT TTTTCGAAGGTTCTCTGAGCTACCAACTCTTTGAACCGAGGTAACTGGCTTGGAGGAGCGCAGTCACCAAAACTTGTCC TTTCAGTTTAGCCTTAACCGGCGCATGACTTCAAGACTAACTCCTCTAAATCAATTACCAGTGGCTGCTGCCAGTGGTG CTTTTGCATGTCTTTCCGGGTTGGACTCAAGACGATAGTTACCGGATAAGGCGCAGCGGTCGGACTGAACGGGGGGTTC GTGCATACAGTCCAGCTTGGAGCGAACTGCCTACCCGGAACTGAGTGTCAGGCGTGGAATGAGACAAACGCGGCCATA ACAGCGGAATGACACCGGTAAACCGAAAGGCAGGAACAGGAGAGCGCACGAGGGAGCCGCCAGGGGGAAACGCCTG GTATCTTTATAGTCCTGTCGGGTTTCGCCACCACTGATTTGAGCGTCAGATTTCGTGATGCTTGTCAGGGGGGCGGAGC CTATGGAAAAACGGCTTTGCCGCGGCCCTCTCACTTCCCTGTTAAGTATCTTCCTGGCATCTTCCAGGAAATCTCCGCCC CGTTCGTAAGCCATTTCCGCTCGCCGCAGTCGAACGACCGAGCGTAGCGAGTCAGTGAGCGAGGAAGCGGAATATATC CTGTATCACATATTCTGCTGACGCACCGGTGCAGCCTTTTTTCTCCTGCCACATGAAGCACTTCACTGACACCCTCATCA GTGCCAACATAGTAAGCCAGTATACACTCCGCTAGCGCAGAAAGGCCCACCCGAAGGTGAGCCAGGTGATTACATTTG GGCCCTCATTAGAAAAACTCATCGAGCATCAAATGAAATTGCAATTTATTCATATCAGGATT

\section{MBP-srt}

ATGAAAATCGAAGAAGGTAAACTGGTAATCTGGATTAACGGCGATAAAGGCTATAACGGCCTGGCTGAAGTCGGTAAG AAATTCGAGAAAGATACCGGAATTAAAGTCACCGTTGAGCATCCGGATAAACTGGAAGAGAAATTCCCACAGGTTGCG GCAACTGGCGATGGCCCTGACATTATCTTCTGGGCACACGACCGCTTTGGTGGCTACGCTCAATCTGGCCTGTTGGCTG AAATCACCCCGGACAAAGCGTTCCAGGACAAGCTGTATCCGTTTACCTGGGATGCCGTACGTTACAACGGCAAGCTGA TTGCTTACCCGATCGCTGTTGAAGCGTTATCGCTGATTTATAACAAAGATCTGCTGCCGAACCCGCCAAAAACCTGGGA AGAGATCCCGGCGCTGGATAAAGAACTGAAAGCGAAAGGTAAGAGCGCGCTGATGTTCAACCTGCAAGAACCGTACTT CACCTGGCCGCTGATTGCTGCTGACGGGGGTTATGCGTTCAAGTATGAAAACGGCAAGTACGACATTAAAGACGTGGG CGTGGATAACGCTGGCGCGAAAGCGGGTCTGACCTTCCTGGTTGACCTGATTAAAAACAAACACATGAATGCAGACAC 
CGATTACTCCATCGCAGAAGCTGCCTTTAATAAAGGCGAAACAGCGATGACCATCAACGGCCCGTGGGCATGGTCCAA CATCGACACCAGCAAAGTGAATTATGGTGTAACGGTACTGCCGACCTTCAAGGGTCAACCATCCAAACCGTTCGTTGGC GTGCTGAGCGCAGGTATTAACGCCGCCAGTCCGAACAAAGAGCTGGCGAAAGAGTTCCTCGAAAACTATCTGCTGACT GATGAAGGTCTGGAAGCGGTTAATAAAGACAAACCGCTGGGTGCCGTAGCGCTGAAGTCTTACGAGGAAGAGTTGGCG AAAGATCCACGTATTGCCGCCACCATGGAAAACGCCCAGAAAGGTGAAATCATGCCGAACATCCCGCAGATGTCCGCT TTCTGGTATGCCGTGCGTACTGCGGTGATCAACGCCGCCAGCGGTCGTCAGACTGTCGATGAAGCCCTGAAAGACGCG CAGACTCGTATCACCAAGGGCAGCCTGCCGGAAACCGGTGGCTAA

\section{Fn10-His-srt}

ATGCTGGTTCCGCGTGGATCCTCTGATGTTCCGAGGGACCTGGAAGTTGTTGCTGCGACCCCCACCAGCCTACTGATCA GCTGGGATGCTCCTGCTGTCACAGTGAGATATTACAGGATCACTTACGGAGAGACAGGAGGAAATAGCCCTGTCCAGG AGTTCACTGTGCCTGGGAGCAAGTCTACAGCTACCATCAGCGGCCTTAAACCTGGAGTTGATTATACCATCACTGTGTA TGCTGTCACTCCGCGTGGAGACTGGAACGAAGGTAGCAAGCCAATTTCCATTAATTACCGAACAGGTAAAAAAGGTAA AGGCGGTCATCACCATCACCATCACCTGCCGGAAACCGGTGGTTAA

\section{5f7-His-srt}

ATGCTGGTTCCGCGTGGATCCTCTGATGTTCCGAGGGACCTGGAAGTTGTTGCTGCGACCCCCACCAGCCTACTGATCA GCTGGGATGCTCCTGCTGTCACAGTGAGATATTACAGGATCACTTACGGAGAGACAGGAGGAAATAGCCCTGTCCAGG AGTTCACTGTGCCTGGGAGCAAGTCTACAGCTACCATCAGCGGCCTTAAACCTGGAGTTGATTATACCATCACTGTGTA TGCTGTCACTCCGCGTGGAGACTGGAACGAAGGTAGCAAGCCAATTTCCATTAATTACCGAACAGGTAAAAAAGGTAA AGGCGGTCATCACCATCACCATCACCTGCCGGAAACCGGTGGTTAA

\section{Trx-5f7-His-srt}

ATGAGCGATAAAATTATTCACCTGACTGACGACAGTTTTGACACGGATGTACTCAAAGCGGACGGGGCGATCCTCGTC GATTTCTGGGCAGAGTGGTGCGGTCCGTGCAAAATGATCGCCCCGATTCTGGATGAAATCGCTGACGAATATCAGGGC AAACTGACCGTTGCAAAACTGAACATCGATCAAAACCCTGGCACTGCGCCGAAATATGGCATCCGTGGTATCCCGACT CTGCTGCTGTTCAAAAACGGTGAAGTGGCGGCAACCAAAGTGGGTGCACTGTCTAAAGGTCAGTTGAAAGAGTTCCTC GACGCTAACCTGGCCGGTTCTGGTTCTGGCCATATGCACCATCATCATCATCATTCTTCTGGTCTGGTGCCACGCGGTTC TGGTATGAAAGAAACCGCTGCTGCTAAATTCGAACGCCAGCACATGGACAGCCCAGATCTGGGTACCGACGACGACGA CAAGTCTGGCATGGAAGTGCAGCTGGTGGAAAGCGGCGGCGGCCTGGTGCAGGCGGGCGGCAGCCTGCGCCTGAGCT GCGCGGCGAGCGGCATTACCTTTAGCATTAACACGATGGGCTGGTATCGCCAGGCGCCGGGCAAACAGCGCGAACTGG TGGCGCTGATTATCAGCATTGGCGATACCTATTATGCGGATAGCGTGAAAGGCCGCTTTACCATTAGCCGCGATAACGC GAAAAACACCGTGTATCTGCAGATGAACAGCCTGAAACCGGAAGATACCGCGGTGTATTATTGCAAACGCTTTCGCAC CGCGGCGCAGGGCACCGATTATTGGGGCCAGGGCACCCAGGTGACCGTGAGCAGCCATCACCATCACCATCACCTGCC GGAAACCGGTGGTTAA

\section{sfGFP-His-srt}

ATGCGTAAAGGCGAAGAGCTGTTCACTGGTGTCGTCCCTATTCTGGTGGAACTGGATGGTGATGTCAACGGTCATAAGT TTTCCGTGCGTGGCGAGGGTGAAGGTGACGCAACTAATGGTAAACTGACGCTGAAGTTCATCTGTACTACTGGTAAACT GCCGGTACCTTGGCCGACTCTGGTAACGACGCTGACTTATGGTGTTCAGTGCTTTGCTCGTTATCCGGACCATATGAAG CAGCATGACTTCTTCAAGTCCGCCATGCCGGAAGGCTATGTGCAGGAACGCACGATTTCCTTTAAGGATGACGGCACGT ACAAAACGCGTGCGGAAGTGAAATTTGAAGGCGATACCCTGGTAAACCGCATTGAGCTGAAAGGCATTGACTTTAAAG AAGACGGCAATATCCTGGGCCATAAGCTGGAATACAATTTTAACAGCCACAATGTTTACATCACCGCCGATAAACAAA AAAATGGCATTAAAGCGAATTTTAAAATTCGCCACAACGTGGAGGATGGATCTGTGCAGCTGGCTGATCACTACCAGC AAAACACTCCAATCGGTGATGGTCCTGTTCTGCTGCCAGACAATCACTATCTGAGCACGCAAAGCGTTCTGTCTAAAGA TCCGAACGAGAAACGCGATCATATGGTTCTGCTGGAGTTCGTAACCGCAGCGGGCATCACGCATGGTATGGATGAACT GTACAAACATCACCATCACCATCACCTGCCGGAAACCGGTGGTTAA

\section{His-sfGFP-srt}

ATGCATCACCATCACCATCACCGTAAAGGCGAAGAGCTGTTCACTGGTGTCGTCCCTATTCTGGTGGAACTGGATGGTG ATGTCAACGGTCATAAGTTTTCCGTGCGTGGCGAGGGTGAAGGTGACGCAACTAATGGTAAACTGACGCTGAAGTTCA TCTGTACTACTGGTAAACTGCCGGTACCTTGGCCGACTCTGGTAACGACGCTGACTTATGGTGTTCAGTGCTTTGCTCGT TATCCGGACCATATGAAGCAGCATGACTTCTTCAAGTCCGCCATGCCGGAAGGCTATGTGCAGGAACGCACGATTTCCT TTAAGGATGACGGCACGTACAAAACGCGTGCGGAAGTGAAATTTGAAGGCGATACCCTGGTAAACCGCATTGAGCTGA AAGGCATTGACTTTAAAGAAGACGGCAATATCCTGGGCCATAAGCTGGAATACAATTTTAACAGCCACAATGTTTACA TCACCGCCGATAAACAAAAAAATGGCATTAAAGCGAATTTTAAAATTCGCCACAACGTGGAGGATGGATCTGTGCAGC TGGCTGATCACTACCAGCAAAACACTCCAATCGGTGATGGTCCTGTTCTGCTGCCAGACAATCACTATCTGAGCACGCA AAGCGTTCTGTCTAAAGATCCGAACGAGAAACGCGATCATATGGTTCTGCTGGAGTTCGTAACCGCAGCGGGCATCAC GCATGGTATGGATGAACTGTACAAACTGCCGGAAACCGGTTAA

\section{GST-His-srt}

ATGCCACCATACACCGTTGTTTACTTTCCTGTTCGTGGTAGATGTGCCGCTCTTCGTATGTTATTGGCCGATCAAGGACA ATCATGGAAGGAAGAAGTTGTTACTGTTGAAACCTGGCAAGAAGGTTCATTAAAGGCCTCATGTTTATACGGACAATT GCCAAAGTTTCAAGATGGAGATTTGACCTTATACCAATCTAACACTATTCTTCGTCATTTGGGTCGTACCTTGGGATTGT ACGGAAAGGATCAACAAGAAGCTGCCTTAGTTGATATGGTTAACGATGGTGTTGAGGATCTTAGATGCAAATACATTT CTCTTATATACACCAACTACGAAGCCGGAAAGGATGATTACGTTAAGGCTCTTCCAGGACAATTAAAGCCATTTGAAAC CCTTTTGTCACAAAACCAAGGTGGCAAAACCTTTATTGTTGGAGATCAAATTTCATTTGCCGATTACAACTTGCTTGATC TTCTTCTTATTCATGAAGTTTTGGCCCCAGGATGTCTTGATGCTTTTCCATTATTGTCCGCCTACGTTGGTAGACTTTCAG CTAGACCAAAATTGAAAGCCTTCTTAGCCTCTCCAGAATACGTTAACCTTCCTATTAACGGAAACGGGAAGCAACATCA CCATCACCATCACCTGCCGGAAACCGGTGGTTAA 


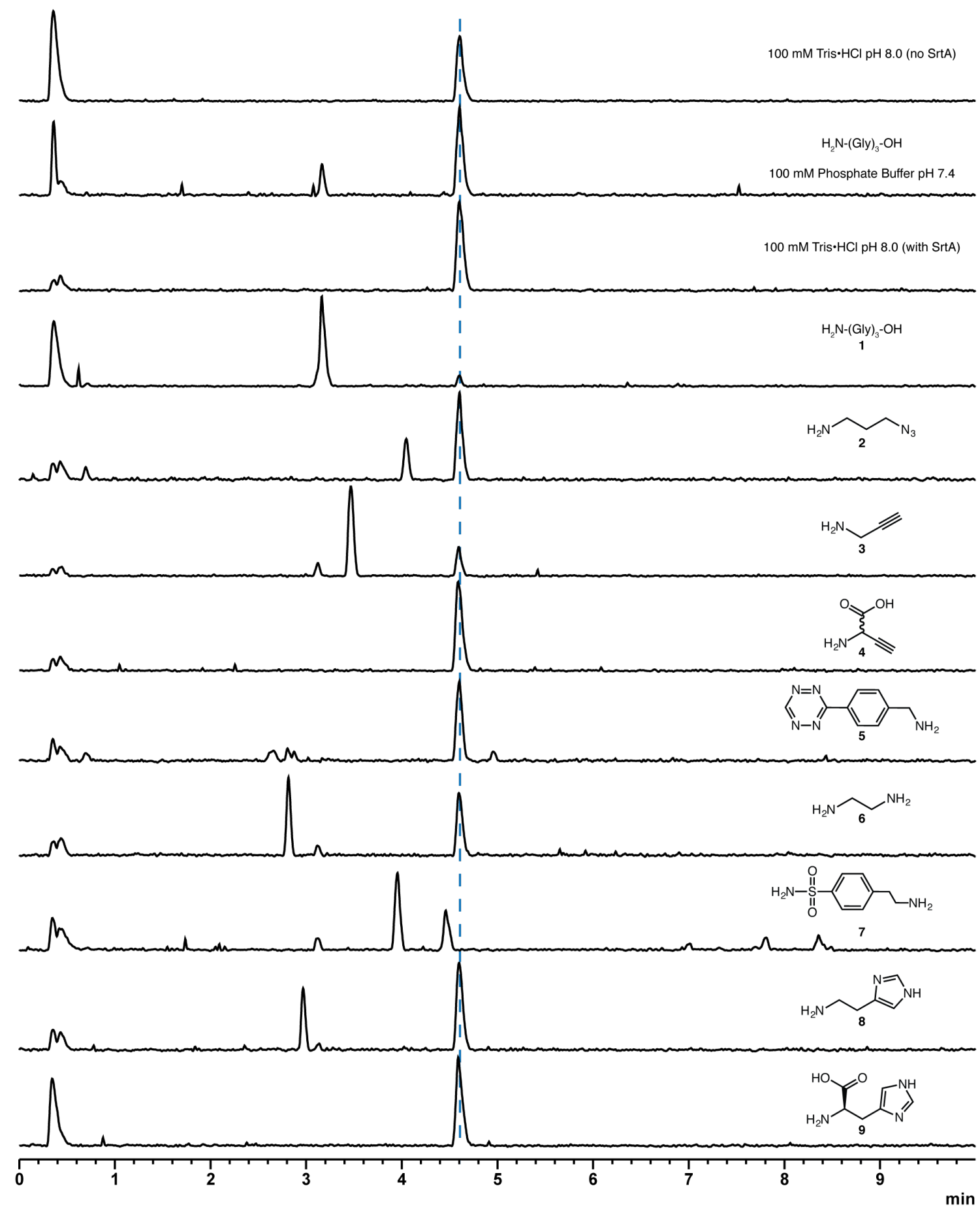

Supplementary Figure S1. Buffer and amine screen. Peptide LPETGSW (1 mM) was incubated with SrtA7M $(20 \mu \mathrm{M})$ for 4 hours at $37^{\circ} \mathrm{C}$ with amines in either $100 \mathrm{mM}$ sodium phosphate buffer $\mathrm{pH}$ 7.4 or Tris. $\mathrm{HCl} \mathrm{pH} \mathrm{8.0,} \mathrm{followed} \mathrm{by} \mathrm{quenching} \mathrm{with} 9$ volumes of $0.8 \%$ formic acid and analysis by negative-mode, quadrupole LC-MS. The enzyme shows poor conversion in phosphate buffer with $\mathrm{Gly}_{3}$, and little to no conversion with other amines (not shown). Significant conversion is seen in Tris buffer, but less than in ammonium bicarbonate, particularly with amines $\mathbf{2}$ and $\mathbf{5}$. 


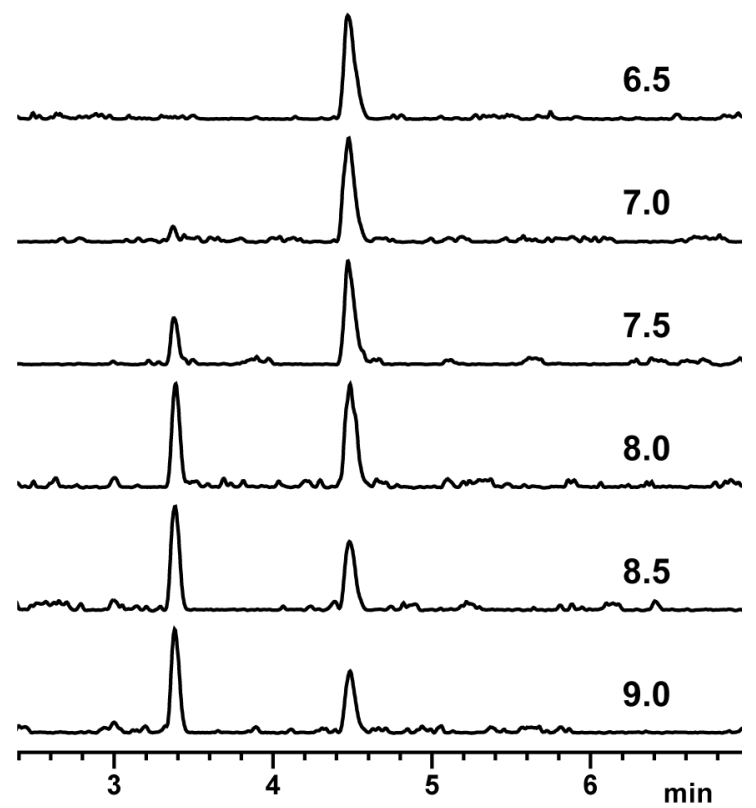

Supplementary Figure S2. Sortase 7M traspeptidation with propargylamine is sensitive to $\mathrm{pH}$. Enzyme $(10 \mu \mathrm{M})$ was incubate with $1 \mathrm{mM}$ LPETGSW and $10 \mathrm{mM}$ propargylamine in $100 \mathrm{mM}$ Tris $\cdot \mathrm{HCl}$ at the $\mathrm{pH}$ indicated for 2 hours at $37^{\circ} \mathrm{C}$, followed by LC/MS analysis. 

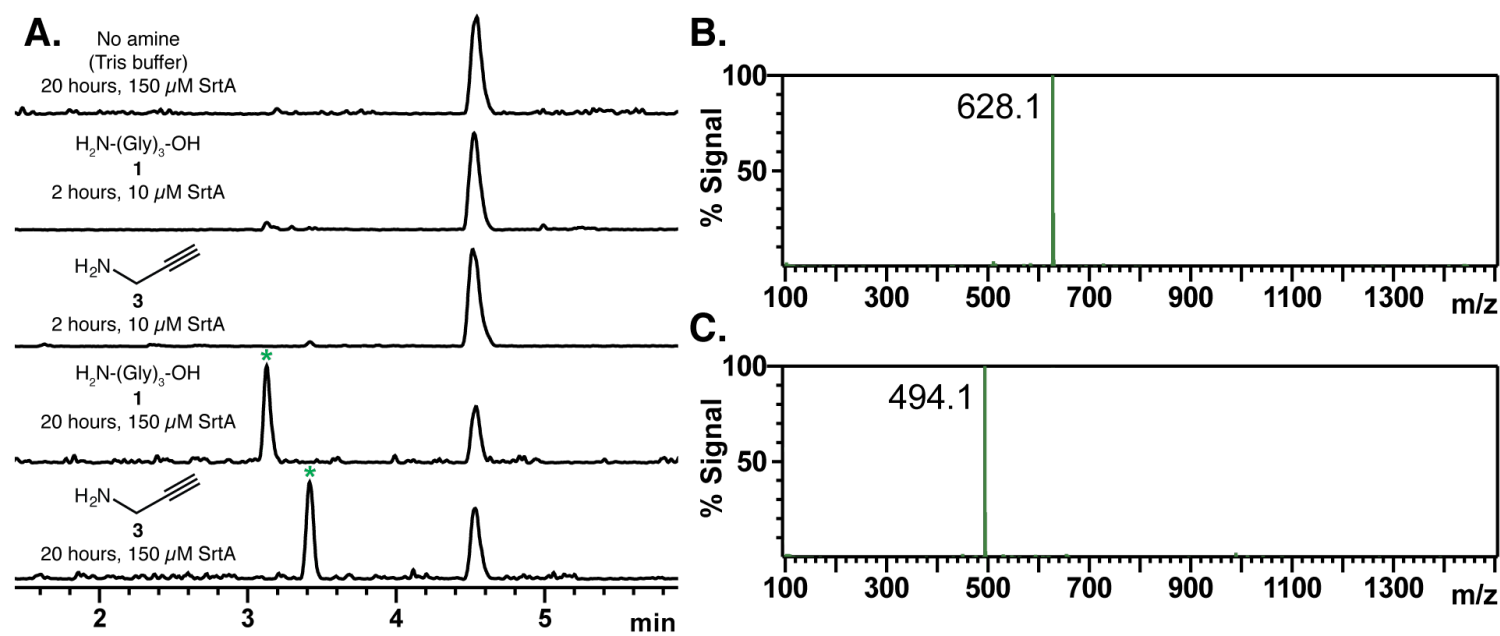

C.

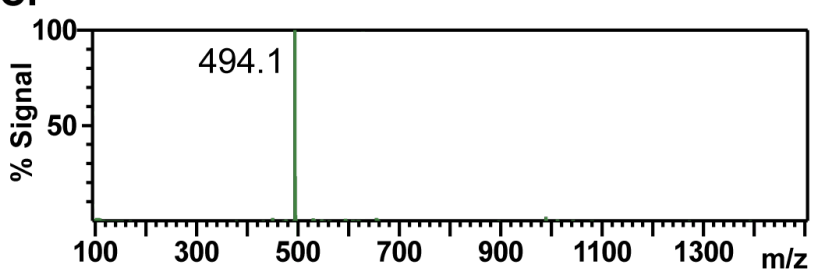

Supplementary Figure S3. Transpeptidation of peptides with wild-type Staphylococcus aureus sortase A. A. LC/MS analysis of WT SrtA transpeptidation of LPETGSW peptide in vitro. SrtA (10 or 150 $\mu \mathrm{M})$ was incubated with peptide $(1 \mathrm{mM})$ and amine $(10 \mathrm{mM})$ in $25 \mathrm{mM}$ Tris $\bullet \mathrm{HCl} \mathrm{pH} 7.5,150 \mathrm{mM}$ $\mathrm{NaCl}$, and $10 \mathrm{mM} \mathrm{CaCl}$ for 2 or 20 hours at $37^{\circ} \mathrm{C}$. The reaction was quenched with 9 volumes of $0.8 \%$ formic acid and analyzed by LC/MS. Negative-mode base-peak chromatograms indicate significant labeling of peptdide as denoted by asterisks (*). B. Mass spectrum of Gly ${ }_{3}$-modified peptide. C. Mass spectrum of propargylamine-modified peptide. 


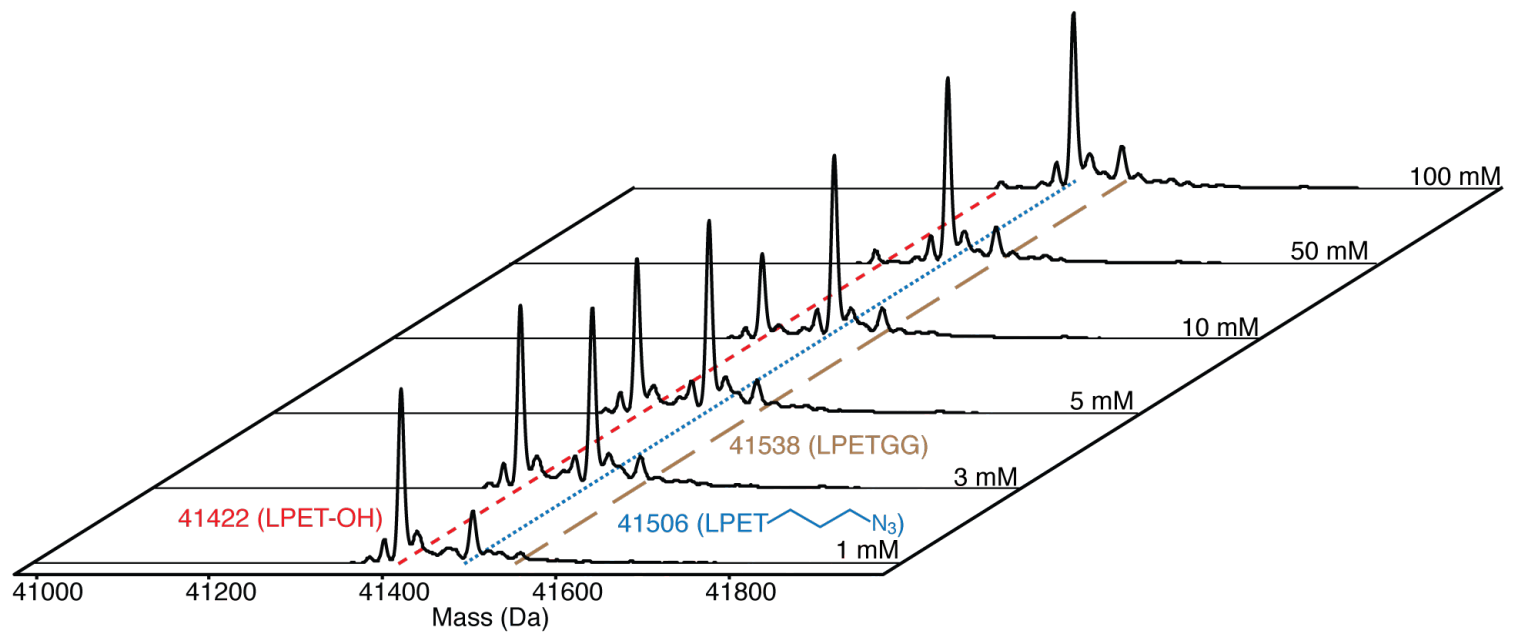

Supplementary Figure S4. Azp concentration screen. MBP $(100 \mu \mathrm{M})$ was incubated with SrtA7M $(10 \mu \mathrm{M})$ for 8 hours at $37^{\circ} \mathrm{C}$ with varying concentrations of Azp, followed by quenching with 9 volumes of $0.8 \%$ formic acid. Lower concentrations show almost complete ammoniolysis, while higher concentrations show high levels of Azp conjugation. 


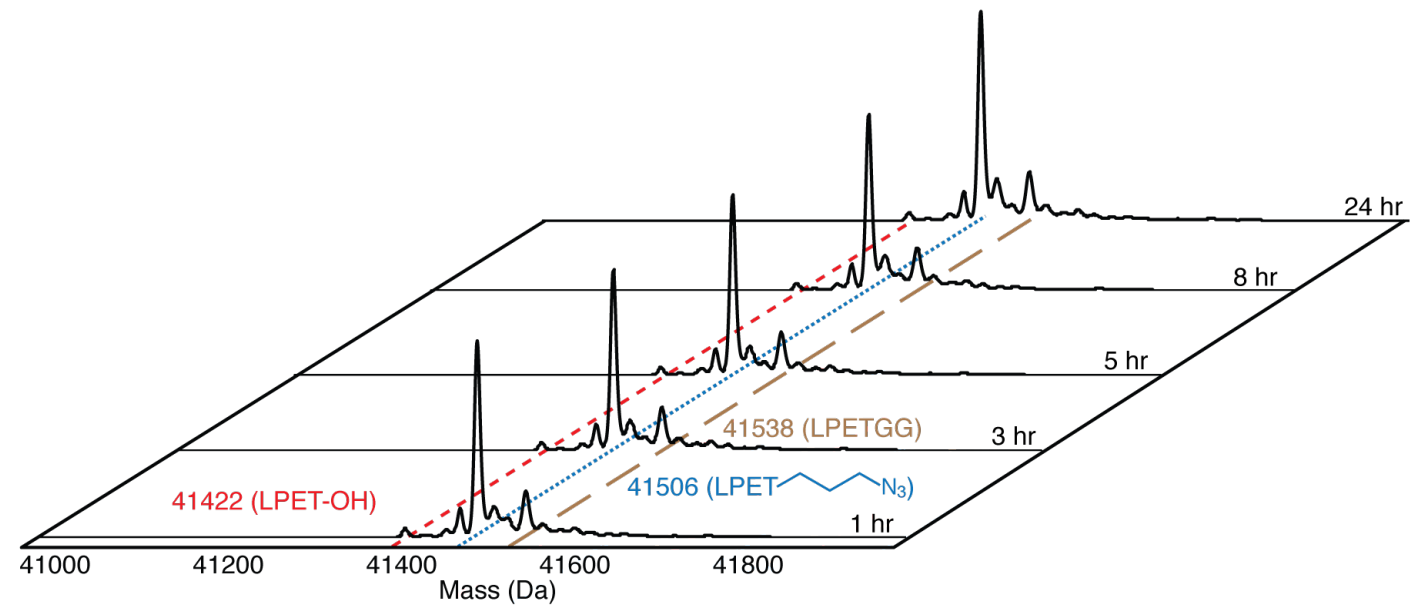

Supplementary Figure S5. Sortase conjugation time course. MBP $(100 \mu \mathrm{M})$ was incubated with SrtA7M $(100 \mu \mathrm{M})$ at $37^{\circ} \mathrm{C}$ with Azp $(100 \mathrm{mM})$. Aliquots were taken at each time point and quenched with 9 volumes of $0.8 \%$ formic acid. The reaction is nearly complete after only 1 hour, with only slight increases in yield in subsequent time points. 
A.

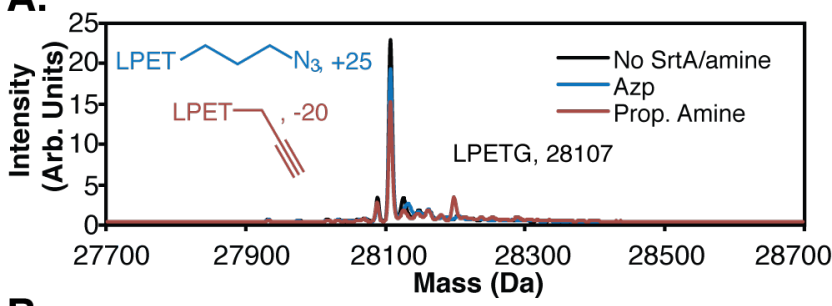

B.

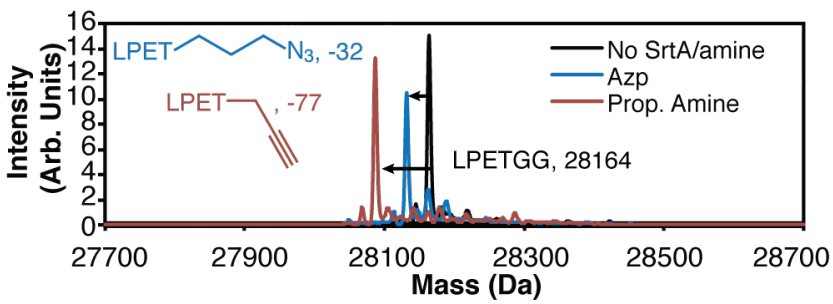

Supplementary Figure S6. In vitro conjugation of sfGFP derivatives. A. His-sfGFP-srt and B. sfGFPHis-srt were incubated with $10 \mu \mathrm{M}$ SrtA7M and 100 $\mathrm{mM}$ Azp or propargylamine for 8 hours at $37^{\circ} \mathrm{C}$. No detectable modification of His-sfGFP-srt took place, but sfGFP-His-srt was completely modified with the desired amines. 


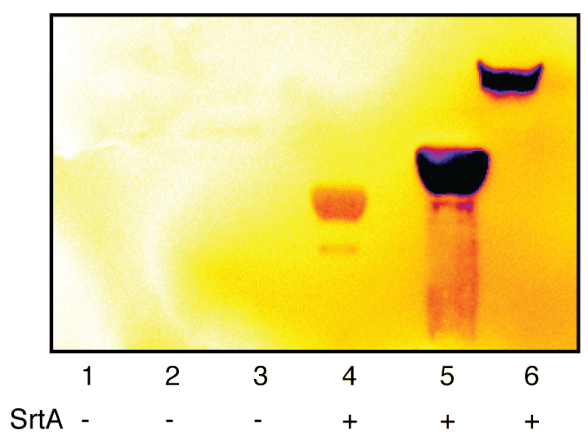

Supplementary Figure S7. Specificity of labeling in vivo. GST-His-srt, GFPHis-srt, and MBP-srt were coexpressed with SrtA7M in the presence of Azp. After 22 hours cells were washed and lysed. Lysate was incubated with biotin DIBAC, run on a $12 \%$ SDS-PAGE gel, transferred to a nitrocellulose membrane, and stained with Neutravidin-horseradish peroxidase. Lanes: 1, 4: GST-His-srt; 2, 5: GFP-His-srt; and 3, 6: MBP-srt. 
A.

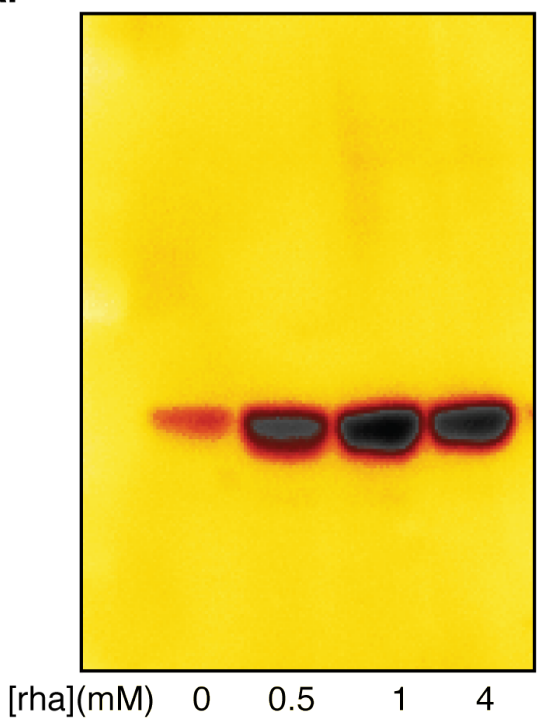

B.

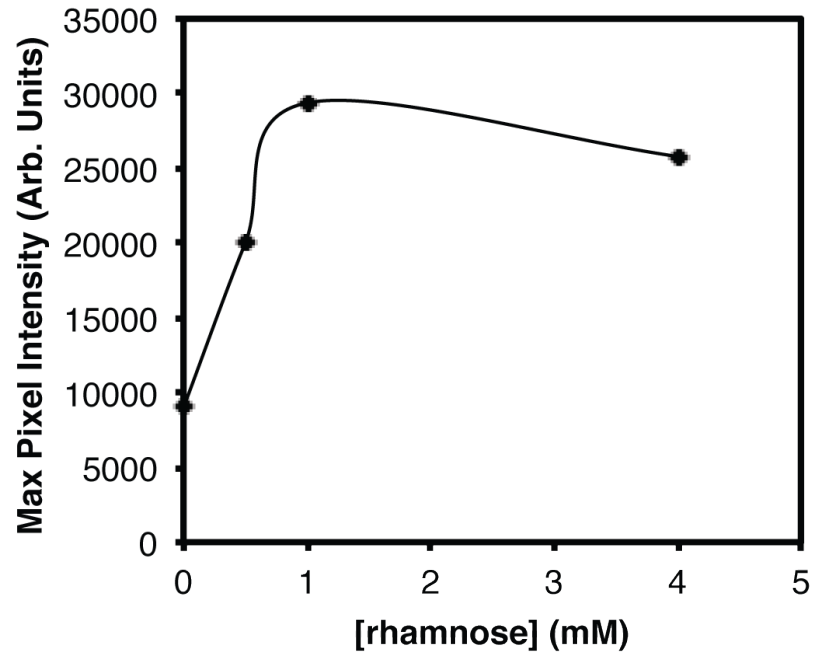

Supplementary Figure S8. Sortase expression screen. Cells containing plasmids for sfGFP-His-srt and sortase were induced with varying concentrations of rhamnose, along with $5 \mathrm{mM}$ Azp. After growth and labeleing overnight at $30^{\circ} \mathrm{C}$, cells were lysed and clarified, then labeled with $500 \mu \mathrm{M}$ biotin-DIBAC for 3 hours. A. Western blot of biotin-DIBAC-labeled protein in lysate, detected using Neutravidin-HRP. Saturating induction of sortase did not increase labeling efficiency over subsaturating rhamnose. B. Gel image was processed in ImageJ to quantify band intensity. 
A.

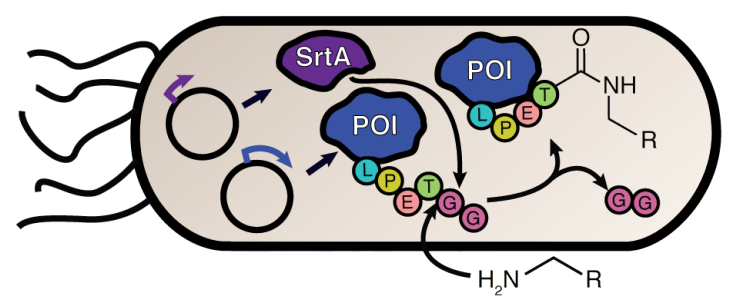

C.

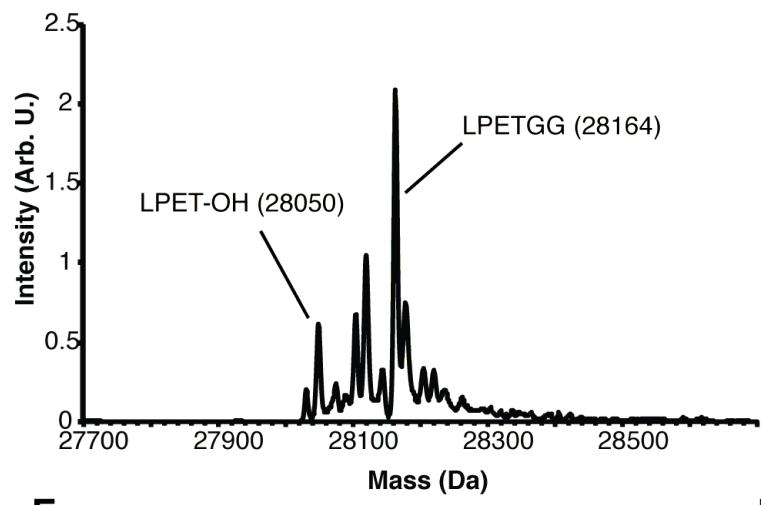

E.

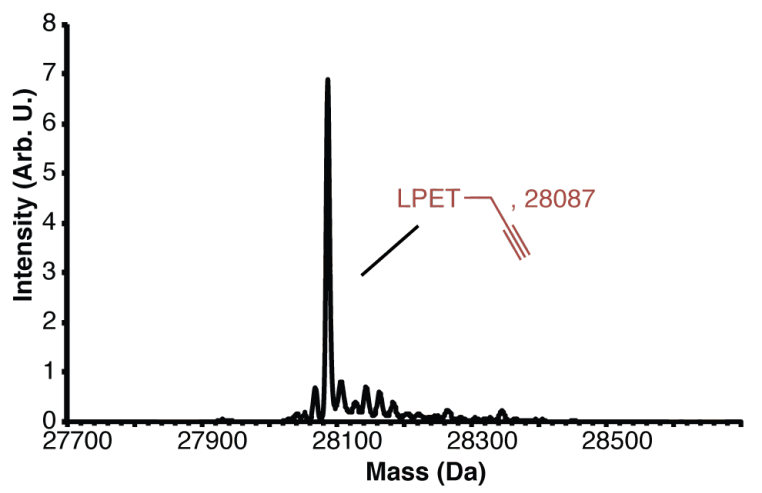

B.
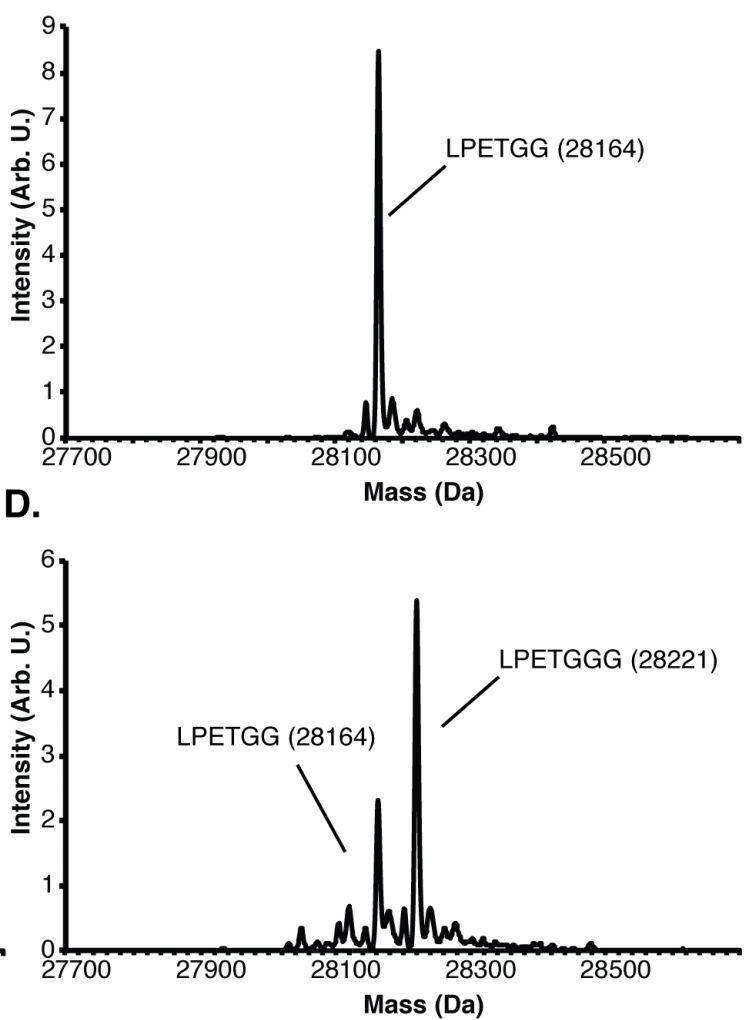

F.

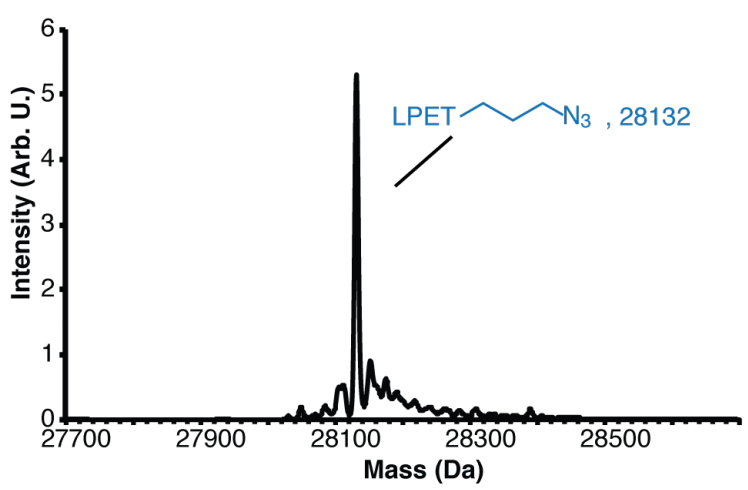

Supplementary Figure S9. In vivo conjugation of sfGFP derivatives. A. Amine ( $25 \mathrm{mM})$ added to culture diffuses into cells coexpressing sortase and the protein of interest. B. sfGFP-His-srt was expressed without sortase or added amine. C. sfGFP-His-srt was coexpressed with SrtA7M without added amine. Several unidentified adducts are visible on the mass spectrum. D. sfGFP-His-srt was coexpressed with SrtA7M with Gly3 added to the culture. E. sfGFP-His-srt was coexpressed with SrtA7M with propargylamine added to the culture. F. sfGFP-His-srt was coexpressed with SrtA7M with Azp added to the culture. B, E, and F appear in Figure 4C, and are expanded here for detail. 